\title{
The Diagnostic Value of Hepatocyte Paraffin Antibody 1 in Differentiating Hepatocellular Carcinoma from non-hepatic Tumors
}

\author{
ADRIAN GOLDIS ${ }^{1}$, NORINA BASA ${ }^{2 *}$, DANIELA LAZAR ${ }^{3 *}$, RAMONA GOLDIS $^{4 *}$, AURA JURESCU $^{5}$, \\ AMADEUS DOBRESCU ${ }^{6}$, ROBERT BARNA ${ }^{5}$, MARIOARA CORNIANU ${ }^{5}$ \\ ${ }^{1}$ Victor Babes University of Medicine and Pharmacy Timisoara, Gastroenterology Department, 2 Eftimie Murgu Sq., \\ 300041, Timisoara, Romania \\ ${ }^{2}$ Victor Babes University of Medicine and Pharmacy Timisoara, Medical Semiology Department I, 2 Eftimie Murgu Sq., \\ 300041, Timisoara, Romania \\ ${ }^{3}$ Victor Babes University of Medicine and Pharmacy Timisoara, Internal Medicine Department IV, 2 Eftimie Murgu Sq., \\ 300041, Timisoara, Romania \\ ${ }^{4}$ Policlinica Algomed, 4 Lucian Blaga Str., 300002, Timisoara, Romania \\ ${ }^{5}$ Victor Babes University of Medicine and Pharmacy Timisoara, Microscopic Morphology Department II, 2 Eftimie \\ Murgu Sq., 300041, Timisoara, Romania \\ ${ }^{6}$ Victor Babeş University of Medicine and Pharmacy Timisoara, Surgery Department II, 2 Eftimie Murgu Sq., 300041, \\ Timisoara, Romania
}

The paper presents approaches the topic of hepatocellular carcinoma (HCC) differential diagnosis with various other malignant tumors, as such differentiation can be in many cases performed only based on a thorough immunohistochemical marker designed for hepatocellular differentiation. Hepatocyte paraffin-1(Hep Par-1), is a specific antibody for hepatocellular tissue that is represented within both healthy and malignant hepatic cells. The paper evaluated the expression of Hep Par-1 on paraffin tissue acquisitions of selected cases of resecable hepatocellular carcinoma referred for curative surgery (20 cases). For the experimental part, mouse anti-human hepatocyte monoclonal antibodies, Hepatocyte Abl, and diluted clones of OCH1E5 with the EnVision technique have been used. The results were suggestive for positive expression of Hep Par-1 in 15 of the 20 cases of HCC (75\%), with various degrees secondary to the differentiation degree (which was positive in all 15 G1-G2 HCCs and negative in 5 G3-G4 HCCs); on the other hand, the study showed a non-homogenous and focal Hep Par-1 distribution malignant tissue engaging a uniform staining of the non-tumorous liver tissue surrounding the lesion. The study did not show Hep Par-1 immunostaining in non-hepatocytic tumors, excepting some focal expression on a gastric adenocarcinoma with clear patchy expression. Our research confirms that Hep Par-1 can be considered a valuable marker in the diagnosis of HCC, although not totally specific; thus, it should be used in a conjugated manner with various other markers useful in hepatocellular differentiation.

Keywords: hepatocellular carcinoma, metastatic carcinoma, Hep Par-1, differential diagnosis of $\mathrm{HCC}$

Hepatocellular carcinoma (HCC) represents the vast majority of primary liver tumors, but the positive histological diagnosis is in many cases hard to be performed especially in relationship with the presence of other primary (as the cholangiocarcinoma) or secondary (various metastases) neoplasms within the liver. Performing the differential diagnosis of HCC requires immunohistochemical (IHC) staining techniques which are on the other hand limited by the fact the there are no reliable IHC markers for hepatocellular differentiation [1,2].

Studies that analyzed the comparative IHC profile of HCC, CC and metastatic adenocarcinomas by evaluating the expression of Hepatocyte Parafin-1 (Hep Par-1), pCEA, mCEA, AFP, CK7, CK19, CK20, CD10, AE1/AE3, CAM5.2, MOC-31 support the idea that HEP Par-1 is a sensitive and specific marker for HCC, useful in differentiating HCC from CC and metastatic adenocarcinomas. The authors noted positive Hep Par-1 expression in 90\% of HCC, $14 \%$ of metastatic adenocarcinomas and the absence of immunoreaction in CC $[1,3]$.

The literature [4] refers to Hep Par-1 and pCEA as possible reliable IHC markers for differentiation hepatocellular tissue, despite the fact that they have been characterized by loe degrees of sensitivity especially in some cases with poor differentiation. Glypican-3 IHC testing shows optimistic results the diagnosis of poorly differentiated HCC

*email:norina.basa@yahoo.com; lazar.daniela@umft.ro; amalia_goldis@yahoo.com 
especially in what differentiation from benign tumors such as hepatic adenomas are concerned. Hence, subsequent research involving a larger number of cases is mandatory for a wider use of such markers. Nevertheless, simultaneous analysis of Hep Par-1 and MOC-31 IGH markers may facilitate the positive diagnosis of HCC in most cases and therefore, can be used as a prerequisite step in the selection of other immunohistochemical markers within workup.

Hep Par-1 antibody is a marker specific for hepatocytes and sensitive on paraffin-embedded sections, reacting with normal and neoplastic hepatocytes. Such antibody acts directly towards hepatocytes mitochondrial antigens and is therefore expressed through a typical granular cytoplasmic staining [3, 5, 6].

The aim of our study was to evaluate the diagnostic utility of Hep Par-1 in differentiating HCC from metastatic carcinoma, taking histopathology as a gold standard.

\section{Experimental part}

The studied material came from patients admitted in the Surgery Clinics of the County and Municipal Clinical Hospitals of Timişoara and it was divided into two groups.

In the first group we included conventional tissue sections from paraffin blocks of 20 patients with clinical diagnosis of hepatic carcinoma (who underwent curative hepatic resection). The second group (six cases) was made up of hepatic tumor fragments obtained by laparoscopy (two cases) and four hepatic resection pieces for non-hepatic tumors. In this study, we did not use samples obtained by hepatic biopsy.

The studied material followed the same procedure of histological processing implying fixation in $10 \%$ formalin for 24 hours, paraffin inclusion and sectioning at $4-5 \mu$. The usual morphological investigation was made on sections stained with hematoxylin-eosin (HE). In all analyzed cases, the initial clinical diagnosis of HCC was confirmed on histological sections stained with HE, allowing the establishment of the histopathological diagnosis, the subtype and degree of differentiation of the hepatic tumor.

\section{Immunohistochemistry and interpretation of immunoreactions}

For the assessment of hepatocyte differentiation, for all cases included in the study we made IHC stainings using the rabbit monoclonal antibody anti-human hepatocytes, Hepatocite Ab-1, clone OCH1E5. IHC reactions were made in the EnVision ${ }^{\circledR}+$ visualization system Dual Link System-HRP (DAB+).

Sections 4-5 $\mu \mathrm{m}$ thick obtained from conventional paraffin tissue blocks were mounted on Superfrost Ultra Plus slides or silanized in order to avoid their detachment during the pretreatment processes. For antigen retrieval, sections were pre-treated by boiling in Target Retrieval solution $(\mathrm{pH}=6.0)$ for 20 minutes at $98-99^{\circ} \mathrm{C}$ and then incubated with the primary antibody Hepatocite Ab-1 diluted 1:40, for 30 minutes at room temperature (clone OCH1E5, DAKO, Carpinteria, CA). After the incubation of the slides with the primary antibody, on sections marked with a special marker we applied the secondary antibody and then the chromogen (DAB - 3.3 diaminobensidine), followed by the counterstaining of nuclei with hematoxylin for 2-3 minutes and mounting of the sections with Entelan.

Normal hepatocytes surrounding the tumor served as positive internal control of the reaction. We obtained a distinct staining pattern, with granular cytoplasmic localization in shades of brown. Normal hepatocytes express Hep Par-1 in the cytoplasm, the staining being intense, diffuse and granular, without preferential expression, with decrease of staining intensity in compressed hepatocytes immediately adjacent to the tumor. Bile ducts or non-hepatocyte cells were Hep Par-1 negative.

For the cases included in the second group, IHC reactions were applied for the monoclonal antibody Hep Par-1 (clone OCH1E5) and the anti-CD20 monoclonal antibody, clone L26 (a marker of B line neoplastic cells). We used the diluted primary antibody, with pretreatment by boiling in citrate buffer $\mathrm{pH}=6$, for 30 minutes at $80^{\circ} \mathrm{C}$.

In order to demonstrate the neuroendocrine nature of metastatic hepatic tumors, we analyzed chromogranin A (Chr A) and synaptophysin (Syn) using the anti-Chr A, clone LK 2H10 (Enzo Diagnostic, INC, New-York) and anti-Syn, clone Syn38 (Ready Systeme, Zurzach/Switzerland) antibodies. Deparaffinized sections were stained IHC, with pretreatment by boiling at $80^{\circ} \mathrm{C}$, incubation with the primary antibody diluted $1 / 200$ and visualization with DAB.

The anti-HMB-45 antibody was used to confirm the melanocytic nature of tumor cells. Sections were pretreated by boiling in citrate buffer at $\mathrm{pH} 9$ for 20' and then incubated with the primary antibody for 30 minutes. To determine estrogen receptors (ER), we used the mouse monoclonal antibody clone 1D5, code M7047 (dilution 1:250); to highlight the progesterone receptors (PR), we used clone PgR 636, dilution 1:50.

\section{Results and discussions}

The first group was made up of 20 patients, 12 (60\%) men and 8 (40\%) women, who underwent curative surgical resection for hepatic cancer (complete tumor resection, defined by the absence of microscopic tumor in resection margins).

REV.CHIM.(Bucharest) $70 \bullet$ no. $12 \downarrow 2019$ 
Patients were between 52 and 69 years old, with a mean age of 66.3 years; 12 cases were located in the right hepatic lobe (RHL), 4 cases in the left hepatic lobe (LHL) and another 4 bilaterally. The presence of hepatic viral infection was identified in $5(25 \%)$ cases: infection with hepatitis B virus (HBV) in 2 cases and with hepatitis $\mathrm{C}$ virus $(\mathrm{HCV})$ in 3 cases. None of the patients presented viral co-infection (HVB+HVC). The hepatic background surrounding the tumor was cirrhotic in 4 cases and with active chronic hepatitis in 6 cases. The patients presented single or multiple tumor nodules, with variable sizes, between 1 and $7.5 \mathrm{~cm}$. Maximum size of the tumor was $7.5 \mathrm{~cm}$, histological size being calculated as the sum of all tumor nodules identified macro- and microscopically in the resected liver. Clinical diagnosis was confirmed on sections stained HE, all 20 resected tumors being classified as HCC.

The studied hepatic tumors were histopathologically graded according to the criteria of Edmondson and Steiner [7]: well differentiated (grade I carcinomas), moderately differentiated (grade II carcinomas) and poorly differentiated/anaplastic (grade III and IV carcinomas). Staging of the HCC was made according to AJCC/UICC staging criteria for cancer [8,9]: we identified 3 HCC in stage I, 6 cases in stage II, 8 cases of stage III and 3 cases of stage IV carcinomas (Fig. 1).

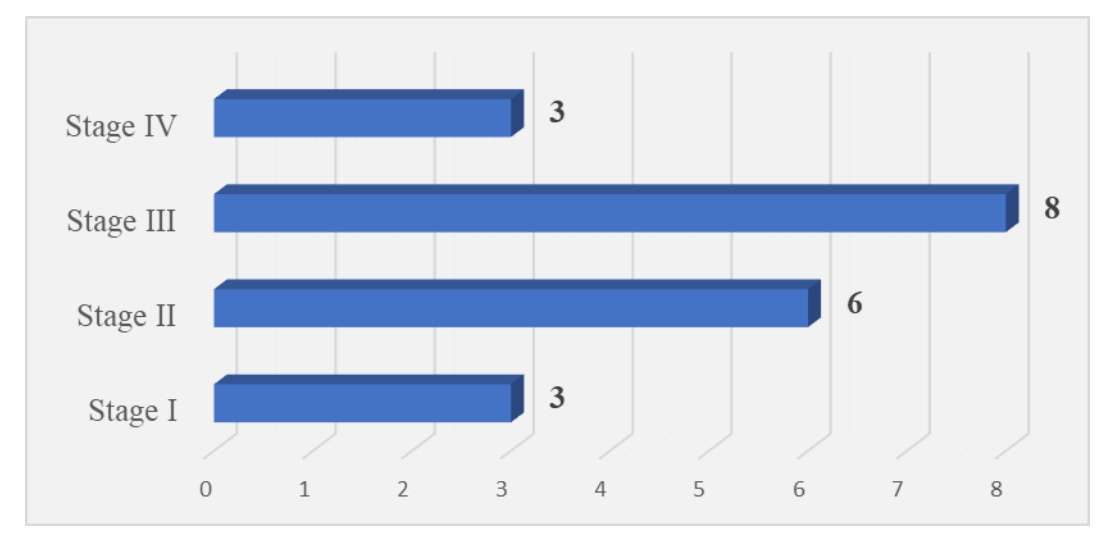

Fig. 1. Staging of the studied hepatic carcinomas

In the tissue surrounding the tumor, with lesions of chronic hepatitis and cirrhosis, we observed a diffuse granular Hep Par-1 expression in hepatocytes, without staining of bile duct epithelium.

In all 20 HCCs evaluated, we noted a granular cytoplasmic Hep Par-1 staining pattern. Focal immunostaining was defined by the presence of less than $5 \%$ positive cells, involving significant positive immunoreactions only when $\geq 5 \%$ of hepatocytes was stained. We observed positive Hep Par-1 expression in $15(75 \%)$ of the 20 HCC. There were three cases of HCC which showed positive staining with areas of focal immunostaining in less than 5\% of hepatocytes; within this group, only two cases have been initially negative and presented focally positive Hep Par-1 expression after repeating the staining on sections obtained from the spare tumor piece.

HCC presented a heterogeneous positive Hep Par-1 expression, according to their degree of differentiation (Fig. 2). All G1-G2 HCC expressed Hep Par-1, while poorly differentiated/anaplastic tumors G3-G4 were negative for Hep Par-1.

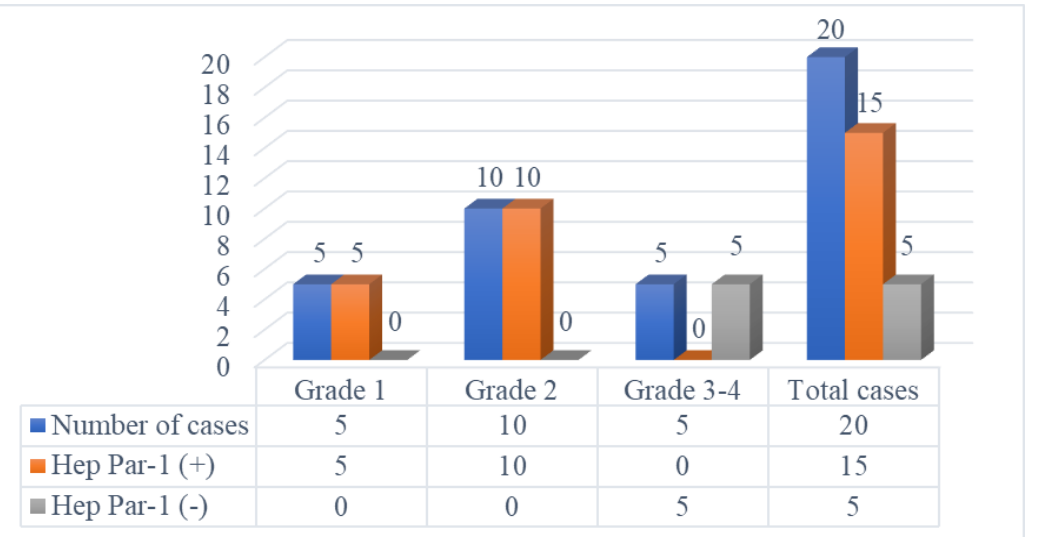

Fig. 2. Hep Par-1 expression according to $\mathrm{HCC}$ grade

We observed a uniform, intense and diffuse Hep Par-1 expression in HCC with an acinar/pseudoglandular pattern (Fig. 3a and c), as well as a trabecullar pattern and a heterogeneous immunoreaction in areas with clear cells, fat deposition and bile secretion (Fig. 3b). Overall, HCC immunostaining with Hepatocite Ab-1 showed a heterogeneous or patchy distribution, in 
contrast to the uniform staining of the non-neoplastic liver surrounding the tumor. Anaplastic carcinomas expressed Hep Par-1 in the hepatic tissue adjacent to the tumor, but not in neoplastic cells (Fig. 1d).

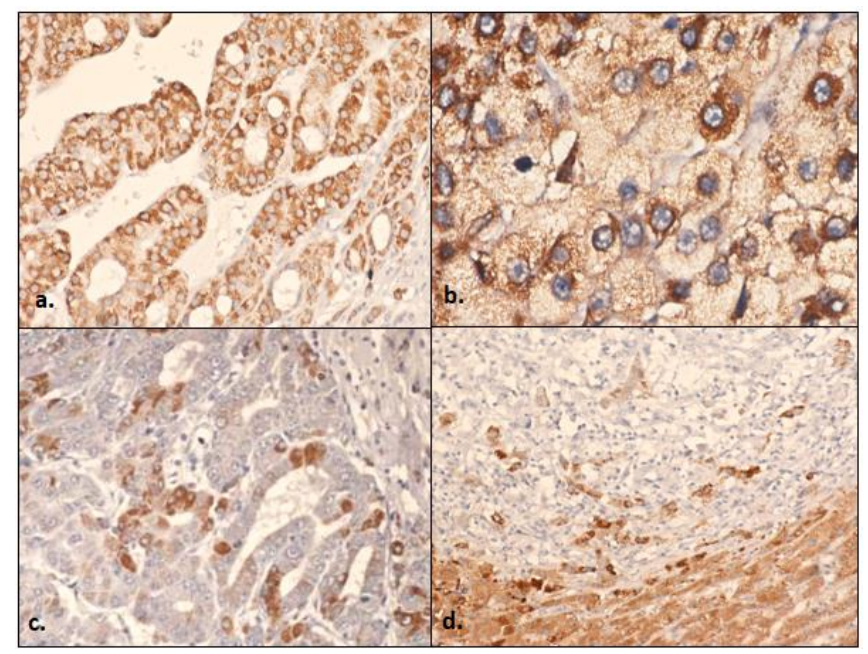

Fig. 3. Hep Par-1 expression in HCC:

a. Acinar HCC with Hep Par-1 intense and diffuse expression; b. HCC with clear cells and fat deposition. Heterogeneous Hep Par-1 exprsession; c. Positive Hep Par-1 expression with focal immunostaining; d. Anaplastic HCC with Hep Par-

1 negative expression on tumor cells

The second group comprised six cases and was made up of hepatic tumor fragments obtained by laparoscopy (two cases) and four hepatic resection pieces from patients operated for various tumor pathologies.

On HE sections, all six cases were diagnosed as secondary (metastatic) hepatic tumors. In the two hepatic tumors obtained after laparoscopic interventions, we identified the hepatic metastasis of a colorectal mucinous adenocarcinoma and a malignant melanoma, respectively. All four resected hepatic tumors were metastatic, the primary tumors being: one gastric carcinoma with signet-ring cells, one well differentiated neuroendocrine carcinoma of the pancreas, one mammary carcinoma and one case of intenstinal non-Hodgkin diffuse malignant lymphoma. These patients with secondary hepatic tumors did not have hepatic cirrhosis or chronic hepatitis as a background disease.

On tissue sections with normal liver adjacent to hepatic metastases, the percentage of hepatocytes that stained with Hep Par-1 was 90-100\%. In gastric carcinoma with signet ring cells, we observed positive Hep Par-1 expression in over 5\% of tumor cells. The metastases of adenocarcinoma, intestinal lymphoma, neuroendocrine carcinoma, malignant melanoma and mammary carcinoma to the liver (Fig. 4) were Hep Par-1 negative, with characteristic IHC profile (Table 1).

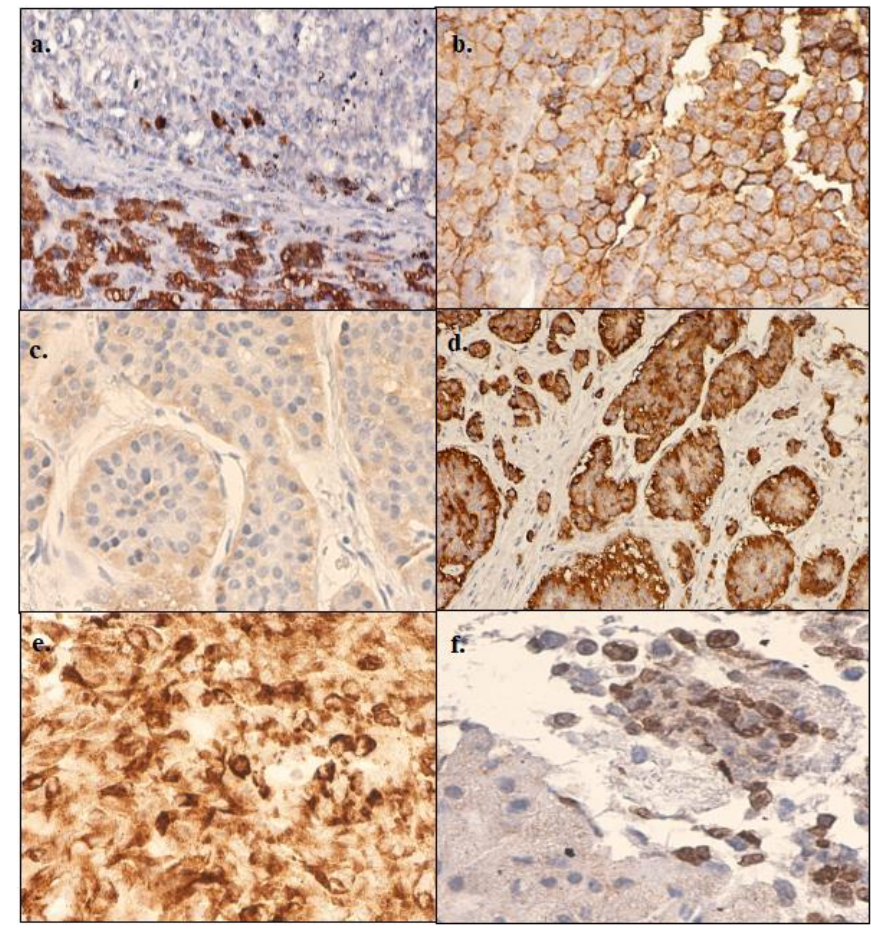

Fig. 4. Hep Par-1 expression in different malignant tumors: a. and b. Hepatic metastasis of a cecal non-Hodgk in malignant lymphoma (hep Par-1-; CD20+);

$\mathrm{c}$ and d. Hepatic metastasis of a neuroendocrine carcinoma (Hep Par-1-; Syn+; CrgA+);

e. Hepatic metastatsis of a malignant melanoma (HMB45+);

f. Hepatic metastasis of a mammary carcinoma $(\mathrm{ER}+)$ 
Table 1

HEP PAR-1 EXPRESSION AND IHC PROFILE OF NON-HEPATOCYTE TUMORS FROM GROUP 2

\begin{tabular}{|c|c|c|}
\hline Tumors & $\begin{array}{c}\text { Hep Par-1 + cases } \\
\mathbf{2 5 \%} \text { positive tumor cells }) / \\
\text { total number of cases }\end{array}$ & IHC profile \\
\hline Gastric carcinoma with signet ring cells & $1 / 1$ & HepPar-1+; CK7+ \\
\hline Colorectal mucinous adenocarcinoma & $0 / 1$ & HepPar-1-; CK20+; CK7- \\
\hline Intestinal lymphoma & $0 / 1$ & Hep Par-1-; CD20+ \\
\hline Mammary carcinoma & $0 / 1$ & Hep Par-1-; ER+; PR+ \\
\hline Malignant melanoma & $0 / 1$ & HepPar-1-; HMB45+; S100+ \\
\hline Neuroendocrine carcinoma & $0 / 1$ & HepPar-1-; CrgA+; Syn+ \\
\hline
\end{tabular}

Hepatocellular carcinoma (HCC) is the most common primary hepatic neoplasia, its distinction (on usual stainings) from other malignant tumors, like cholangiocarcinoma (CC) and metastatic carcinomas being sometimes difficult in the absence of a trustworthy IHC marker for hepatocellular differentiation.

To date, Hep Par 1 (Hepatocyte paraffin-1) antibody (clone OCH1E5.2.10; OCH1E5) has become available on the market and showed positive reactions with both normal and neoplastic hepatocytes. Hep Par 1 designed as specific for hepatocytes, has been first cited in 1993 by Wennerberg et al. [6] and is referred to as a not only sensitive but also specific IHC marker for differentiation of hepatocellular tissue on paraffin included tissue sections. Hep Par-1 acts directly against hepatocellular mitochondrial antigens and is expressed by a characteristic cytoplasmic granular staining [10]. Subsequently, some studies [11-13] considered it useful in differentiating clear cell HCC from other specific clear cell malignancies and embryonic-type hepatoblastoma from small cell tumors in children; nevertheless, it has been used also in the differential diagnosis of HCC with pseudoglandular pattern from CC and metastatic liver tumors.

The skin, smooth and skeletal muscles, mesothelium, lymph nodes, spleen, lungs, breast, esophagus, stomach, intestine, pancreas, biliary tract, kidneys, urinary bladder, adrenal glands, prostate, endometrium and ovaries are almost always negative. In some cases we observed an intense focal staining in the mucosa of the small bowel [11-13].

Various published studies state that Hep Par-1 antibody has a specificity of $79 \%$ and a high sensitivity for liver differentiation [3, 5, 6]. Aproximately $80-100 \%$ of HCCs react with Hep Par-1, with a granular staining pattern, moderate/intense and diffuse (and onlu occasionally focal) [14]. The distribution of the immunoreactions does not correlate with the degree of HCC diiferentiation [15].

Of the non-hepatocytic tumors that are Hep Par-1 positive, ovarian carcinoma with hepatoid differentiation $[16,17]$ and gastric carcinoma with signet ring cells were described to usually express a diffuse cytoplasmic staining, while mammary and colorectal cancers are Hep Par-1 negative [18, 19].

We evaluated the utility of the Hep Par-1 antibody in differentiating HCC from CC and hepatic metastatic tumors, by assessing the expression of Hep Par-1 on tissue sections from two groups of patients.

We obtained: a) positive Hep Par-1 immunoreaction in $75 \%$ of HCCs, with a heterogeneous or patchy pattern in tumor tissues and a uniform staining of the non-neoplastic liver tissue surrounding the tumor; b) Hep Par-1 expression correlated with the degree of HCC differentiation (with the absence of immunostaining in poorly differentiated/ anaplastic carcinomas G3-G4); c) uniform Hep Par-1 expression, intense and diffuse in acinar/ pseudoglandular and trabecular HCC, heterogeneous in clear cell HCC with fat deposition and bile secretion, as well as the absence of immunoreactions in anaplastic carcinomas, the results being similar to those available in literature.

Chu et al. [18] noted Hep Par-1 immunoreaction in 92\% of HCC, with granular cytoplasmic staining pattern (showing that Hep Par-1 is a relatively specific marker for HCC) and correlated the level of Hep Par-1 expression with the nuclear degree (Hep Par-1 expression in all HCC with 1 and 2 nuclear degree, in 84\% of HCCs with degree 3 and $50 \%$ of degree 4 tumors) and growth pattern (positive Hep Par-1 in $98 \%$ of trabecular, pseudoglandular and sclerosing HCC and $81 \%$ of HCC with solid pattern).

Mivervini et al. [11] and Chu et al. [18] observed Hep Par-1 negative immunoreactions in poorly differentiated HCC, as compared to well differentiated HCC, while other studies do not report such correlations. In our study, poorly differentiated HCC were Hep Par-1 negative.

In all HCC with 1 and 2 nuclear degree, we found positive immunoreactions, sometimes multifocal and heterogeneous, supporting the fact that poorly differentiated HCC lose their immunoreactivity to Hep Par-1. False negative results can be due to the heterogeneous and sometimes focal staining pattern of HCC, especially on biopsy material.

Assessing Hep Par-1 expression in HCC (on pieces obtained at necropsy) according to the differentiation degree and histological pattern, Kumagai et al. [10] describes a decrease in Hep Par-1 expression with the histological degree of the tumor, suggesting that Hep Par-1 is a useful marker for the diagnosis and differentiation of HCC. After 
evaluating the role of Hep Par-1 in distinguishing HCC from CC and hepatic metastatic carcinomas, Shiran et al. [1] observes an intense and diffuse Hep Par-1 expression in benign hepatocytes, heterogeneous Hep Par-1 staining in HCC - irrespective of their differentiation degree, occasional positive immunostaining in CC and negative reaction in metastatic carcinomas; Hep Par-1 sensitivity and specificity for HCC was $82.1 \%$ and $93.3 \%$, respectively, suggesting the use of Hep Par-1 along with other markers.

Although Hep Par-1 is a marker with high specificity for HCC, it also reacts with gastric carcinomas; Fan et al. [14] obtained positive Hep Par-1 expression in $47 \%$ of gastric carcinomas, with $\geq 5 \%$ staining in $35 \%$ of cases. Poorly differentiated carcinomas or those with signet ring cells reacted more frequently and more intensely than well differentiated ones. The authors reported frequent Hep Par-1 immunoreaction in conventional gastric carcinomas, irrespective of "hepatoid" differentiation, these results limiting its utility because metastatic gastric adenocarcinoma often imposes differential diagnosis with a hepatic tumor.

Hep Par-1 expression was described focally in 5/6 gastric carcinomas with "hepatoid" differentiation (staining being attributed to areas with hepatocellular differentiation, distinguished by positivity for AFP and CEAp) [17] and in 3/10 gastric carcinomas with signet ring cells [6].

Chu et al. [18] reported Hep Par-1 immunoreaction in 2/12 conventional gastric carcinomas and in 2 carcinomas with hepatoid differentiation, in 5/21 pulmonary carcinomas, in 4/24 ovarian carcinomas, in 4/9 neuroendocrine carcinomas and occasionally in some tumors considered to be Hep Par-1 negative. Other studies noted Hep Par-1 intense expression in $73 \%$ of HCC and in non-hepatic tumors (pulmonary adenocarcinoma $4 \%$, gallbladder $4.17 \%$, pancreas $4.17 \%$, stomach $4.95 \%$, small intestine $9.09 \%$, adrenal carcinoma $6.25 \%$, paraganglioma $11.11 \%$, malignant melanoma $4.17 \%$, colon adenoma with high grade dysplasia $2.04 \%$ ), suggesting that Hep Par-1 is a very specific marker for HCC, although occasionally it is expressed in some non-hepatic tumors [20]. Although Hep Par-1 is 100\% sensitive for hepatoblastomas and it does not stain other tumors such as neurobloastoma and nefroblastoma, Fasano et al. [13] described Hep Par-1 expression in 2/9 yolk sac tumors, these being AFP-positive, similar to hepatoblastomas.

Analyzing the possible prognostic value of Hep Par-1 in patients with surgically resected HCC, Mondada et al. [21] finds Hep Par-1 expression, considering it a favorable prognostic factor in small size tumors. Otherwise, tumor size and growth has been already linked to multiple cellular and plasmatic markers hyper expression [22-25].

Assessing Hep Par-1 expression on a group made up of hepatic tumor fragments obtained laparoscopically (two cases) and pieces of hepatic resection (four cases), in all six cases we identified metastatic hepatic tumors, with Hep Par-1 expression in the metastasis of a gastric carcinoma with signet ring cells.

\section{Conclusions}

This IHC study on the hepatocellular differentiation marker demonstrated Hep Par-1 expression in $75 \%$ of the studied hepatic carcinomas. We did not obtain false positive/negative reactions, correct processing of tissue pieces and usage of internal positive control aiding the correct interpretation and quantification of the immunoreactions. In two Hep Par-1 negative cases, after repeating the IHC staining, we observed focal Hep Par-1 expression.

Hep par-1 is a reliable immunohistochemical marker for cases of HCC. It can be used along with other markers in morphologically difficult cases when differential diagnosis lies between poorly differentiated HCC and metastatic carcinoma of liver.

\section{References}

1. SHIRAN, M.S., ISA, M.R., SHERINA, M.S., RAMPAL, L., HAIRUSZAH, I., SABARIAH, A.R., Malays. J. Pathol., 28, no. 2 , 2006 , p. 87.

2. ANTON, E., BOtNARIUC, N., ANCUTA, E., DOROFTEI, B., CIOBICA, A., ANTON, C., Medical-Surgical Journal-Revista MedicoChirurgicala, 119, no. 2, 2015, p. 410.

3. LAU, S.K., PRAKASH, S., GELLER, S.A., ALSABEH, R., Hum. Pathol., 33, 2002, p. 1175.

4. KAKAR, S., GOWN, A.M., GOODMAN, Z.D., FERRELL, L.D., Arch. Pathol. Lab. Med., 131, 2007, p. 1648.

5. MORRISON, C., MARSH, Jr W., FRANKEL, W.L., Mod. Pathol., 15, 2002, p. 1279.

6. WENNERBERG, A.E., NALESNIK, M.A., COLEMAN, W.B., Am. J. Pathol., 143, 1993, p. 1050.

7. EDMONDSON, H.A., STEINER, P.E., Cancer, 7, 1954, p. 462.

8. SOBIN, L.H., WITTEKIND, C., (eds.), UICC: TNMclassification of malignant tumors. 5th edition. New York,Wiley-Liss, 1997 , pp. 74-77.

9. GREENE, F.L., PAGE, D.L., FLEMING, I.D., AJCC Cancer Staging Manual, 6th edition New York Springer, 2001 , pp. 132-138.

10. KUMAGAI, I., MASUDA, T., SATO, S., ISHIKAWA, K., Hepatol. Res., 20, 2001, p. 312.

11. MIVERVINI, M.I., DEMETRIS, A.J., LEE, R.G., CARR, B.I., MADARIAGA, J., NALESNIK, M.A., Mod. Pathol 10, 1997, p. 686.

12. MURAKATA, L.A., ISHAK, K.G., NZEAKO, U.C., Mod. Pathol., 13, 2001, p. 874.

13. FASANO, M., THEISE, N.D., NALESNIK, M., GOSWAMI, S., GARCIA DE DAVILA, M.T., FINEGOLD, M.J., et al., Mod. Pathol., 11, 1998, p. 934.

14. FAN, Z., VAN DE RIJN, M., MONTGOMERY, K., ROUSE, R.V., Modern Pathology, 16, no. 2, 2003 , p. 137.

15. LAMPS, L.W., FOLPE, A.L., Adv. Anat. Pathol., 10, 2003, p. 39.

16. PITMAN, M.B., TRIRATANACHAT, S., YOUNG, R.H., OLIVA, E., Int. Gynecol. Pathol., 23,2004, p. 58.

17. MAITRA, A., MURAKATA, L.A., ALBORES-SAAVEDRA, J., Am. J. Clin. Pathol., 115, 2001 , p. 689.

18. CHU, P.G., ISHIZAWA, S., WU, E., WEISS, L.M., Am. J. Surg. Pathol., 26, 2002, p. 978. 
19. CHU, P.G., WEISS, L.M., Am. J. Clin. Pathol., 121, 2004, p. 884.

20. LUGli, A., TORNILlO, L., MIRLACHER, M., BUNDI, M., SAUTER, G., TERRACCIANO, L.M., Am. J. Clin. Pathol., 122, no. 5, 2004, p. 721.

21. MONDADA, D., BOSMAN, F.T., FONTOLLIET, C., SEELENTAG, W.K., Virchows Arch., 448, no. 1, 2006 , p. 35.

22. TOADER, E., BANCU, A., MITRICA, D.E., CONSTANTINESCU, G., STEFANESCU, G., BALAN, G.G., Romanian Journal of Morphology and Embryology, 60, no. 1, 2019, p. 181.

23. BEREA, G., BALAN, G.G., SANDRU, V., SIRBU, P.D., Rev. Chim. (Bucharest), 68, no. 6, 2017, p. 1341.

24. CATINEAN, A., MOTOCU, R., FETICA, B., MEZEI, A., Medical Ultrasonography, 21, 2019, p. 96. DOI: 10.11152/mu-1560

25. GOLDIS, A., GOLDIS, R., CORNIANU, M., BASA, N., LAZAR, D., DOBRESCU, A., LAZAR, F., Rev. Chim. (Bucharest), 70, no. 6, 2019, p. 2198

Mnauscript received: 11.12 .2019 